\title{
Gastric Mixed Adenocarcinoma
}

National Cancer Institute

\section{Source}

National Cancer Institute. Gastric Mixed Adenocarcinoma. NCI Thesaurus. Code C67526.

An adenocarcinoma that arises from the gastric mucosa and is characterized by the presence of both glandular and poorly cohesive malignant cellular components. 